\title{
MEMÓRIA E OS MECANISMOS DE VIGILÂNCIA EM AS BRUXAS DE SALÉM DE ARTHUR MILLER
} \\ Antonius Poppelaars* \\ Sandra Luna**
}

RESUMO: Arthur Miller escreveu As Bruxas de Salém (1953), peça sobre uma caça às bruxas no século XVII, como metáfora da caça aos comunistas no Macarthismo, um período de perseguição nos Estados Unidos. Em ambos os momentos, a peça-chave da perseguição era a "delação": instar um suspeito a acusar outros. Em 1956, Miller, interrogado por simpatias comunistas, negou-se a delatar, reforçando a peça como denuncia de repressão. Os objetivos deste artigo são conectar a peça ao Macarthismo, aplicando, baseado em Pêcheux, regularização, memória social, memória discursiva, silenciamentos, (não)-ditos, implícitos, (não)-inscrição na memória e baseado em Foucault, mecanismos de vigilância. Conclui-se que a peça, referindo-se ao século XVII e ao Macarthismo, oferta-se como documento que pode ser recuperado pela memória coletiva como exemplo dos mecanismos de vigilância e dos conceitos baseados em Pêcheux, permitindo que a peça possa ser retomada e citada em outros casos de perseguição.

Palavras-chave: As Bruxas de Salém de Arthur Miller, Mecanismos de Vigilância, Memória, Perseguição.

\section{INTRODUÇÃO}

No dia 21 de junho de 1956, o dramaturgo norte-americano Arthur Miller (19152005) foi interrogado pelo Comitê de Atividades Antiamericanas (House of UnAmerican Activities Committee - HUAC) por ter solicitado um passaporte para assistir à estreia da sua peça As Bruxas de Salém (The Crucible) na Bélgica, segundo informa Andrew Glass (2013) em artigo jornalístico. O HUAC, que então vigiava de perto artistas e intelectuais, considerou Miller suspeito de ter simpatias comunistas e

\footnotetext{
*Mestrando em Letras na Universidade Federal da Paraíba. E-mail: antoniuspopulus@gmail.com

** Doutora em Letras. Professora da Universidade Federal da Paraíba, atuando no Programa de PósGraduação em Letras. E-mail: lunasand@uol.com.br
} 
antiamericanas, entrevendo em sua intenção de viajar uma estratégia para fazer propaganda comunista e antiamericana no exterior.

Na ocasião, Miller foi indagado pelo Comitê sobre seu conhecimento acerca de outras pessoas que tivessem simpatias comunistas e antiamericanas, mas o dramaturgo recusou-se a delatar outros, negando ter conhecimento de nomes que pudessem constar na lista de suspeitos. Como resultado de sua postura, não apenas o passaporte lhe foi negado, mas Miller foi ainda condenado por desacato. A sentença, uma multa de quinhentos dólares ou trinta dias na prisão, foi pouco mais tarde anulada. O artigo de Glass (2013), ao fazer referências ao Macarthismo, como um tempo de suspeição e perseguição nos Estados Unidos da década de 1950, associando esse momento de repressão à reação pessoal de Arthur Miller, que se negou a delatar companheiros, e articulando esses acontecimentos à trama da peça As Bruxas de Salém (1953), de fato, acorda a memória do leitor, ensejando reflexões adicionais.

Isto porque, nesta peça, que retoma as circunstâncias históricas ocorridas na cidade de Salém nos Estados Unidos entre 1692-1693, uma comunidade de colonizadores Puritanos vivencia uma caça às bruxas, quando pessoas suspeitas de envolvimento com o demônio passam a ser acusadas e condenadas por uma corte que favorece e estimula a delação de outros. Nos acontecimentos históricos de Salém, os moradores sentiam-se instados a delatar seus vizinhos sobre a prática de bruxaria para salvar seus próprios pescoços do cadafalso.

Em meados dos anos 50 do século $X X$, o estímulo, assim como o impulso à delação, reaparece na vida social dos Estados Unidos pela caça aos comunistas. Ironicamente, a caça aos comunistas resulta na intimação do próprio Miller diante do HUAC. O dramaturgo torna-se, então, vítima desses jogos de acusações, vivenciando em sua própria experiência o mecanismo persecutório contra o qual escreveu.

A peça de Miller, As Bruxas de Salém, relaciona ficcionalmente os dois momentos de perseguição, o de Salém e do HUAC. Assim, a peça torna-se um drama histórico que, enquanto representa a caça às bruxas de Salém, serve de metáfora à caça aos comunistas durante o Macarthismo, quando a delação faz-se novamente peça-chave para isenção de culpa, já que a acusação de outros abre os portais da libertação do acusado, nem sempre importando aos inquisidores se as delações proferidas por via de opressão recairiam sobre pessoas inocentes.

O objetivo geral deste artigo consiste em fomentar dados de leitura sob uma ótica que nos permita enquadrar a peça As Bruxas de Salém em relação alegórica ao Macarthismo. A bem da verdade, essa tem sido uma vertente de estudos frequentemente percorrida na fortuna crítica de Miller. Especificamente, no entanto, focaliza-se a articulação metafórica entre os dois contextos (da caça às bruxas e da caça aos comunistas), analisando-se processos de regularização e conceitos de memória social, memória discursiva e a noção de implícitos formulados por Michel Pechêux (1999), aplicando-os à peça de Miller e à suas conexões com os procedimentos do HUAC. Adicionalmente, será explicado e aplicado à obra de Miller, em conexão com a caça às bruxas e da caça aos comunistas, o que Michel Foucault (1998) chamou de mecanismo de vigilância.

\section{O Macarthismo}


O Macarthismo ${ }^{1}$ representou um período de intensa perseguição ao comunismo, numa fase da história em que os Estados Unidos vivenciam a Guerra Fria. Nesse enquadramento ideológico que prioriza o patriotismo e a devoção aos princípios liberais apregoados pelo país, não foram poucos os acusados de terem simpatias comunistas, de serem espiões da União Soviética, ou de serem "antiamericanos". O mais feroz acusador da época foi o senador Joseph McCarthy, que exerceu seu mandato de 1947 a 1957 e começou uma verdadeira caça aos comunistas. Tendo emprestado seu nome ao próprio movimento repressor e punitivo, McCarthy faleceu em 1957, desprezado e desacreditado (FITZGERALD, 2007), mas o legado de suas perseguições ficou impresso na memória social e discursiva do país.

O HUAC, o Comitê de Atividades Antiamericanas, que exerceu um papel marcante durante a época do Macarthismo, havia sido fundado décadas antes, em 1938, para investigar deslealdade aos Estados Unidos e desbaratar organizações subversivas. O comitê retomou seu poder investigativo depois da Segunda Guerra Mundial, sobressaindo-se em suas funções ao fim da década de 1940, quando desperta entre o povo estadunidense a chamada red scare (medo ou terror vermelho), ou seja, o medo que se instalou no país em relação a atividades comunistas e antiamericanas.

Durante o Macarthismo, principalmente o mundo de entretimento e das artes passou a ser investigado. Muitos atores, autores e diretores foram intimados a comparecer diante do comitê para assumir simpatias e/ou acusar outros de simpatias comunistas. Os acusados eram colocados numa lista negra, The Hollywood Blacklist, e banidos do trabalho ou demitidos. Os que se recusavam a colaborar eram condenados por desacato (FINKELMAN, 2006). Para escapar à lista negra, muitos artistas "confessaram" ter conexões comunistas e deram nomes de outros supostos comunistas em declarações não raramente falsas.

\section{As Bruxas de Salém}

Vários estudiosos e críticos literários da obra de Miller perceberam a conexão entre a trama da peça As Bruxas de Salém e os acontecimentos relacionados ao Macarthismo. Por exemplo, Harold Hobson (1978, p. 227) observou que "a peça do Sr. Arthur Miller sobre a caça às bruxas em Massachussetts do século XVII mantém um olho firmemente fixo nos presentes inquéritos anticomunistas nos Estados Unidos" ${ }^{2}$. Outros críticos, tais como, Brooks (1978), Bentley (1978), e Warshow (1978) mencionaram a conexão entre a peça e o Macarthismo.

A peça As Bruxas de Salém (The Crucible), de 1953, constrói-se ficcionalmente com base nos julgamentos históricos de pessoas acusadas de bruxaria na cidade de Salém entre 1692 e 1693. A ação da peça tem início in medias res, numa noite em

\footnotetext{
${ }^{1}$ McCarthyism em Inglês.

2 "Mr. Arthur Miller's play about witch hunting in seventeenth century Massachussetts keeps one eye steadily fixed on the present anti-communist investigations in the United States". Todas as traduções são próprias, exceto quando houver outra indicação.
} 
que um grupo de meninas, dançando na floresta, é flagrado pelo pastor da comunidade. Devido aos preceitos da religião Puritana, dançar era proibido na cidade de Salém. Uma das meninas, Betty, justamente a filha do pastor, cai em estado de choque. Muitos habitantes da cidade acham que a dança e o consequente coma de Betty são oriundos de prática de bruxaria e trabalho do diabo.

Betty, no entanto, acorda do coma, mas, com medo de ser acusada e condenada como bruxa, "confessa" que dançou sob a influência do demônio. As outras meninas do grupo também "confessam", certas de que o reconhecimento público de sua fragilidade face ao poder do demônio faria os religiosos Ihes perdoarem. No entanto, movidas pelo intuito de desviar de forma mais definitiva a atenção dos religiosos sobre suas danças "pecaminosas", as meninas passam a acusar outras pessoas de práticas de bruxaria e de pactos com o diabo. Cria-se, assim, uma rede de incriminação irresponsável, através da qual a suspeita, que em princípio pode recair sobre qualquer um, é afastada por via da transferência e da projeção da suspeição sobre o outro.

Em um tal contexto de terror e histeria, a acusação ao outro vinha de par com uma "confissão", preço da purgação da culpa. A "confissão", o reconhecimento do erro, era a senha para a obtenção do perdão, enquanto que a negação do pacto com o demônio era vista como opção obstinada de permanecer no pacto. Daí que algumas pessoas acusadas, temerosas da punição, "confessavam" serem praticantes de bruxaria para escapar à pena de morte por enforcamento. Outras pessoas, moralmente íntegras, não ousavam proferir "confissões" que sabiam ser falsas, preferindo não mentir perante o Deus que os observava a todos e, em sua obstinação honesta, recusavam-se a admitir terem ligações com o demônio, sendo condenadas à morte por um tribunal de líderes religiosos.

Destacando-se no grupo dos que resistem e não confessam uma culpa que não Ihes pode ser imputada, está John Proctor, o protagonista da trama de Miller, construído nos moldes do heroísmo clássico. Considere-se que, mesmo depois de ter a tradição teatral acolhido como centro do drama moderno o homem comum, a dramaturgia trágica continuou a exigir desse homem comum qualidades extraordinárias, muito embora a própria condição de herói trágico exija também que, na caracterização desses protagonistas, haja motivação para o cometimento de falhas ou erros que se revelarão funestos.

Ex-patrão de Abigail, que é a líder do grupo de meninas que dançou na floresta, John Proctor havia tido com a jovem serva um caso amoroso. Descoberto pela esposa, para salvar o casamento, John Proctor demitiu Abigail, que, tão logo instada a delatar as "bruxas" da comunidade, acusa Elizabeth, a esposa de John, como forma de vingança contra aquela que considera ainda sua rival. Proctor, movido pelo intento de livrar sua esposa e os outros habitantes inocentes de Salém das acusações das meninas, acaba por ser também envolvido no processo e acusado, ele próprio, de bruxaria.

Diante do poder que exerce face aos condenados, John é instado a "confessar" sua ligação com o demônio para salvar a própria vida. O tribunal exige que John Proctor assine uma confissão a ser lida em público. A confissão acusa indiretamente outras pessoas e, sendo um documento oficial, se assinado, marcaria o nome de Proctor como bruxo para a eternidade, ainda que o mesmo pudesse, com a tal "confissão", permanecer vivo. John, que na peça vivencia uma espécie de 
bildungsroman ${ }^{3}$ em direção ao heroísmo, num ato de coragem e resistência, rasga o documento, preservando seu nome e sua honra, com isso sentenciando-se a morrer na forca, porém, fazendo-o como um homem honesto, que não acusou ninguém falsamente.

\section{A memória em Michel Pêcheux e em Miller}

Sobre a memória, Pêcheux $(1999$, p. 56) informa que esta "não poderia ser concebida como uma esfera plena, [...] cujo conteúdo seria um sentido homogêneo", e que "é necessariamente um espaço móvel de divisões, de disjunções de deslocamentos e de retomadas, de conflitos de regularização [...], réplicas de contradiscursos" (p. 56). A peça As Bruxas de Salém, de Miller, traz à luz uma memória que não é homogênea e oferece um contra-discurso.

Aparentemente, a peça dramatiza conflitos religiosos em uma cidade Puritana no século XVII, sem esquecer de destacar desvios e contradições que desafiam qualquer versão não problemática da ideologia e da práxis religiosa. Mais que isso, ao traçar um paralelo entre a histeria religiosa na cidade de Salém e o anticomunismo fanático durante o Macarthismo, Miller põe em destaque mecanismos persecutórios que as próprias ideologias hegemônicas tentam silenciar.

Fato é que, assim como Miller evidencia através da peça que havia motivos não religiosos para a caça às bruxas em Salém, também indicia haver motivos outros além das prerrogativas políticas para a caça aos comunistas durante o Macarthismo. Trata-se, nesses casos, de motivos que não entraram na composição da memória social. Neste respeito, Pêcheux (1999, p. 59) acrescenta que a memória "[...] é feita de esquecimentos, de silêncios. De sentidos não ditos, de sentidos a não dizer, de silêncios e de 'silenciamentos'. Então, existe um processo contraditório na inscrição de um acontecimento na memória. Um acontecimento pode escapar à inscrição na memória ou pode ser absorvido, como se não tivesse acontecido.

De fato, nos acontecimentos de 1692-1693 em Salém, há dados que escaparam à inscrição na memória. Miller confirma na sua autobiografia (1987) e na introdução à peça As Bruxas de Salém que as acusações vividas naquela comunidade Puritana não foram somente o resultado de uma disputa religiosa na forma de uma caça às bruxas. Bigsby (2005, p. 147) afirma que: "Salém em 1692 estava em tumulto [...]. Títulos de terras originais haviam sido cancelados e outros ainda não estavam assegurados. Vizinho [...] olhava para vizinho com desconfiança por medo de suas terras poderem ser reatribuídas"

Então, muitas acusações no episódio da caça às bruxas na cidade de Salém tiveram uma origem financeira. Os acusados que não confessaram e por isso foram executados tiveram seu dinheiro e sua propriedade confiscados. A propriedade confiscada era dividida entre aqueles que acusaram os condenados de bruxaria.

\footnotetext{
${ }^{3}$ Bildungsroman (do alemão da época do romantismo) é um romance de formação. O protagonista é um jovem, que começa a sua formação em conflito com o ambiente em que vive e que é marcado pelos acontecimentos e pelo sofrimento e aprende com eles, provocando uma compreensão melhor do mundo. (E-Dicionário de Termos Literários).

${ }^{4}$ "Salem in 1692 was in turmoil...Original land titles had been cancelled and others not yet secured. Neighbour [...] looked on neighbour with suspicion for fear their land might be reassigned".
} 
Dentre as estratégias adotadas por Miller na composição de sua peça, a ganância aparece como um motivo importante, assim como motivos ignóbeis reaparecem nos acontecimentos históricos relacionados ao Macarthismo, que foram não somente causados por fatores de ideologia política, mas também por inveja quanto a artistas de sucesso.

Neste respeito, Bigsby (2005, p. 164) notou que: "havia, e, aparentemente, não por acaso, a mesma desconfiança de intelectuais em ambos os períodos. Um dos acusadores de Salém [...] denunciou uma mulher mais velha [...], porque ela foi vista lendo livros"5. Numa perspectiva similar, de desconfiança em relação aos intelectuais, o Macarthismo teria sido uma fonte de revanche para políticos frustrados, que nunca haviam tido sucesso intelectual.

Bigsby (2005, p. 164) afirma que: "McCarthy, ele próprio quase em nada um intelectual, fez questão de perseguir e humilhar [...] escritores e professores. Livros eram, de fato, banidos" ${ }^{6}$. Este tipo de revanche, de acordo com Miller, em Uma Vida (1987), nunca foi inscrito nos objetivos oficiais, assim escapando à memória, como se nunca tivesse acontecido.

Pêcheux (1999, p. 52) também explica que a memória discursiva "seria aquilo que face a um texto que surge como acontecimento a ler, vem restabelecer os implícitos". Os implícitos são, por exemplo, citações, retomadas e pré-construídos, que um leitor necessita para entender um texto. A repetição é responsável pela regularização dos implícitos, o "já-dito".

Por exemplo, a conexão que existe entre os acontecimentos ocorridos na Salém histórica, na peça de Miller e as acusações contra Miller pelo HUAC, baseiase num sentido originário e repetido de que acusações recaem sobre uma pessoa má, que deve ser condenada e punida. Na Salém histórica, uma bruxa é uma pessoa má, que deve ser condenada e punida. No caso do Macarthismo, ecoa a repetição das acusações de malignidade, apenas o comunismo torna-se o elemento mal na sociedade.

Entretanto, um acontecimento discursivo pode interromper a regularização e produzir outros implícitos sob a primeira serie de implícitos, assim deslocando e desregulando a primeira série de implícitos. Então, sempre haverá "um jogo de força na memória, sob o choque do acontecimento" (PÊCHEUX, 1999, p. 52). Este jogo busca manter a regularização com os implícitos veiculados, "mas [...] o jogo de força de uma "desregulação" [...] vem perturbar a rede dos "implícitos", como Pêcheux (1999, p. 52) completa.

Uma forma de jogo que causa a perturbação aos implícitos é o jogo da metáfora; porque "[...] a recorrência do item ou do enunciado pode também [...] caracterizar uma divisão da identidade material do item: sob o "mesmo" da materialidade da palavra abre-se então o jogo da metáfora, como outra possibilidade de articulação discursiva", como explica Pêcheux (1999, p. 53). A materialidade da palavra é sensível para ter vários significados. Então, é possível, sob a variação em significados de uma palavra, abrir um jogo de metáfora; uma palavra pode então ser interpretada numa maneira diferente e assim o significado de um item ou enunciado recorrente pode deslocar a regularização.

\footnotetext{
5 "there was, and seemingly not incidentally, the same distrust of intellectuals in both periods. One of the Salem accusers [...] denounced an older woman [...] because she was seen to read books".

6 "McCarthy, himself scarcely an intellectual, made a point of going after and humiliating [...] writers and teachers. Books were, indeed, banned".
} 
Assim, a peça As Bruxas de Salém de Miller figura como um exemplo que provoca conflitos de regularização, usando a noção de metáfora. Um item recorrentemente enunciado na Salém histórica, no Macarthismo, na peça e na audiência de Miller em 1956 é o elemento nome. Esta palavra, o nome, apresenta-se como elemento central que conecta tudo. Como dito acima, tanto na Salém histórica, como na peça de Miller, os acusados de bruxaria eram forçados a delatar, a dar os nomes de outras supostas bruxas.

Durante o Macarthismo, os acusados de comunismo e sentimentos antiamericanos também eram forçados a dar os nomes de outros supostos comunistas. Bigsby (2005, p. 161) explica que: "delatar foi apresentado como um dever nos anos 1950, os professores sobre os alunos, os alunos sobre os professores, da mesma forma como o vizinho era incentivado a informar sobre o vizinho na Salém do século XVII"7. Por exemplo, em As Bruxas de Salém, Giles Corey, amigo de John Proctor, recusa-se a dar o nome de uma pessoa durante um interrogatório a que é submetido. O juiz Hathorne ameaça Giles, acusando-o de desacato:

GILES (hesita) Ora, eu não posso dar o nome dele ao senhor. HATHORNE. E por que não?

GILES (hesita, depois explode) Sabem muito bem por que não! Ele vai para a cadeia se eu der o nome dele! HATHORNE. Isso é desacato ao tribunal! (MILLER, 2009, p. 344) $^{8}$

Ironicamente, três anos depois de ter escrito a cena, Miller se veria diante de uma circunstância semelhante. Instado a dar nomes de supostos comunistas para um tal de Senhor Scherer, um dos membros do HUAC: "há uma pergunta diante da testemunha; a saber, dar os nomes dos indivíduos que estavam presentes nesta reunião do Partido Comunista de escritores comunistas" "(COMMITTEE ON UNAMERICAN ACTIVITIES, 1956, p 4688).

Miller recusou-se a dar nomes e, como Giles na peça, foi ameaçado de desacato por Scherer: "nós não aceitamos os motivos que você tem para se recusar a responder a pergunta [...] se você não responder a pergunta [...] você está condenando-se por desacato" ${ }^{10}$ (COMITTEE ON UN-AMERICAN ACTIVITIES, 1956, p 4688). Sem se deixar intimidar por Scherer, Miller teria respondido "tudo o que posso dizer, senhor, é que minha consciência não me permite usar o nome de outra pessoa"11 (COMMITTEE ON UN-AMERICAN ACTIVITIES, 1956, p 4688).

\footnotetext{
7 "informing was presented as a duty in the 1950s, professors on students, students on professors, as neighbour was encouraged to inform on neighbour in seventeenth-century Salem".

${ }^{8}$ Tradução de José Siqueira.

9 "There is a question before the witness; namely to give the names of those individuals who were present at this Communist Party meeting of Communist writers".

10 "We do not accept the reasons you have for refusing to answer the question [...] if you don't answer the question [...] you are placing yourself in contempt".

11 "All I can say, sir, is that my conscience will not permit me to use the name of another person".
} 
Miller foi condenado por desacato devido a esta resposta, mas o mais importante para o dramaturgo foi que sua consciência e seu nome ficaram limpos. Como Bigsby (2005, p. 163) observa, definitiva e "logicamente, Miller sentiu-se convencido da autenticidade do paralelo entre a América dos anos 1950 e a Salém de 1692"12. Nesse caso, o uso da "recorrência do item ou do enunciado" (PÊCHEUX, 1999, p. 53) do elemento nome na peça de Miller favorece a sua decodificação como metáfora do Macarthismo.

Uma consciência limpa e um nome limpo foram também mais importantes para John Proctor na peça do que a condenação à morte por bruxaria. Como dito acima, Proctor poderia ter salvado sua vida ao assinar a "confissão", uma falsa confissão que o tornaria bruxo e ao mesmo o levaria a acusar outros de bruxaria. Ao recusar-se a assinar a confissão, o herói enuncia um discurso decisivo de resistência, pronunciado a verdade a custo de sua condenação ao sacrifício trágico: "porque é o meu nome! Porque não posso ter outro na minha vida! Como eu posso viver sem o meu nome? Entreguei a minha alma, me deixam ficar com meu nome!" (2009, p. 344). Proctor foi enforcado no cadafalso, mas morreu com uma consciência limpa e um nome limpo, por não ter delatado outros.

Le Goff (2003, p. 535), que considera documentos como monumentos, afirma que "a análise do documento enquanto monumento permite à memória coletiva recuperá-lo [...]". Por isso, os acontecimentos históricos na cidade de Salém, a peça de Miller e o seu depoimento diante do HUAC podem ser lidos como documentos, que se tornaram monumentos que, entrevistos à luz do discurso crítico da peça dramática, evidenciam os não ditos e os implícitos de momentos históricos nos quais a difamação do nome do outro era apontada como caminho para a redenção.

\section{Os mecanismos de vigilância de Michel Foucault}

Em relação às acusações, que constituem a forma de propagação do terror na peça de Miller e que nos permitem relacionar a Salém de século XVII às perseguições aos comunistas na década de XX e à própria intimação de Miller pelo HUAC, pode-se evocar Foucault (1998, p. 210), que nos explica como uma sociedade se entrega a "[...] uma vigilância [...] ao mesmo tempo global e individualizante, separando cuidadosamente os indivíduos que deviam ser vigiados", como no panopticon. O panopticon foi uma invenção de Jeremy Bentham nas prisões na Inglaterra de século XVIII, que funcionava como uma torre para vigiar todo mundo, prisioneiros e até os guardas. Foucault explica o funcionamento do panopticon nos seguintes termos:

O princípio é: na periferia, uma construção em anel; no centro, uma torre; esta possui grandes janelas que se abrem para a parte interior do anel. A construção periférica é dividida em celas, cada uma ocupando toda a largura da construção. Estas

\footnotetext{
12 "No wonder Miller felt convinced of the authenticity of the parallel between fifties America and the Salem of 1692".
} 
celas têm duas janelas: uma abrindo-se para o interior, correspondendo às janelas da torre; outra, dando para 0 exterior, permite que a luz atravesse a cela de um lado a outro. Basta então colocar um vigia na torre central e em cada cela trancafiar um louco, um doente, um condenado, um operário ou um estudante. Devido ao efeito de contraluz, pode-se perceber da torre, recortando-se na luminosidade, as pequenas silhuetas prisioneiras nas celas da periferia. Em suma, inverte-se 0 princípio da masmorra; a luz e o olhar de um vigia captam melhor que o escuro que, no fundo, protegia. (FOUCAULT, 1998, p. 210)

Assim, como descreve Foucault (1998, p. 220), todo mundo "é vigiado por todos ou por alguns outros, trata-se de um aparelho de desconfiança total e circulante", causando "luta, exclusão e resistência de pessoas" com uma opinião diferente, como adiciona Orlandi (1999. p. 61). O poder e as instituições têm uma influência dominante nesta luta, exclusão e resistência, porque um indivíduo é jogado entre deveres e direitos, "que o individualizam e que derivam das diferentes formas de poder" (ORLANDI, 1999, p. 61). Assim, o poder provoca que há confrontos e exclusão, pelos "mecanismos de imposição, de exclusão e os de resistência” (ORLANDI, 1999, p. 61).

Essa desconfiança circulante foi o que aconteceu na Salém no século XVII. Pessoas eram acusadas de bruxaria por qualquer coisa, mais comumente por problemas de relacionamento no seio da vida comunitária. Desafetos, desentendimentos e disputas entre vizinhos ou parentes ensejavam vingança e esta se consubstanciava por via das acusações. As evidências do pacto com o demônio podiam ser derivadas de qualquer gesto, palavra, sinal de comportamento ou marca corporal, apontadas pelo acusador e aceitas pela corte como prova irrefutável de bruxaria.

Compondo o quadro de evidências de comportamento demoníaco, pessoas eram acusadas de terem, por exemplo, causado moléstias em animais, em crianças ou na safra, apenas com sua presença, como observou Miller nas suas pesquisas históricas para a peça, mencionadas na sua autobiografia Uma Vida ${ }^{13}$ (1987, p. 4546). Os escritos dos próprios Puritanos na época evidenciam como eram comuns acusações de bruxaria com base em testemunhos de "aparições", "visagens", não sendo poucas as ocorrências nas quais o acusador imputa ao acusado o crime de bruxaria por ter este projetado sua "sombra" viva no domicílio da vítima enquanto a mesma dormia.

Motivos os mais incríveis, supersticiosos, associados ao inconsciente, ao mundo onírico, ao imaginário de uma comunidade tomada pelos excessos do medo e da culpa fundamentavam as acusações. Não raramente tratava-se de motivações de ordem material, disputas por propriedade ou herança etc. Para além das motivações, o encadeamento perverso de acusações repercute de uma pessoa a outra, tanto na peça de Miller quanto durante o Macarthismo, objetivando-se de forma emblemática na intimação do próprio Miller, convocado a depor e delatar

\footnotetext{
${ }^{13}$ Titulo original: Timebends.
} 
nomes perante o HUAC. De fato, em cada caso, "cada camarada torna-se um vigia" (FOUCAULT, 1998, p. 215).

Tendo em vista o cenário religioso do Puritanismo, assim como as motivações psicológicas e materiais pulsantes em uma comunidade severamente reprimida e repressora, a peça ilustra com efetividade a maneira como a vigilância se torna coletiva e obsessiva, todo mundo é observado por todo mundo, causando histeria e acusações de toda a ordem. Qualquer desculpa serve para acusar o outro. Ninguém está seguro, como sugere Foucault (1998, p. 221), rico ou pobre, importante na comunidade ou não, porque "o ápice e os elementos inferiores da hierarquia estão em uma relação de apoio e de condicionamento recíprocos, eles se "sustentam" (o poder, "chantagem" mútua e indefinida)".

Exatamente este tipo de mecanismo de vigilância, causando um poder "omnividente" (FOUCAULT, 1998, p. 215), foi o que caracterizou a Salém histórica, assim como sua releitura ficcional na peça de Miller e permitiu a interpretação metafórica do passado histórico em associação ao Macarthismo. Os que estão no poder acham que as pessoas tornar-se-ão virtuosas por serem vigiadas. Como Foucault (1998, p. 224) explica: "eles acreditam que as pessoas iriam tornar-se virtuosas pelo simples fato de serem olhadas".

Então, a pressão, o olhar da sociedade faz com que os que têm outra opinião cooperem, porque "o olhar dos outros, o discurso dos outros os impediria de fazer o mal” (FOUCAULT, 1998, p. 216). Então, por medo de exclusão e punição, cooperam com o mecanismo de vigilância. O resultado é que muitos se submetem à opinião da sociedade, a única aceitável, porque "a boa opinião só pode por ser a que reflete a consciência imediata de todo o corpo social” (FOUCAULT, 1998, p. 216). Assim, como notou Bigsby (2005, p.150): "As Bruxas de Salém é um estudo do poder e dos mecanismos pelos quais o poder é sustentado, desafiado e perdido"14.

Por isso, a peça, cuja dramaticidade direciona o sympathos, o sentimento empático da recepção, para os personagens inocentes, acusados injustamente, constitui-se como leitura crítica da própria história. Chamando a si o pathos associado ao sacrifício dos perseguidos e injustiçados, John Proctor projeta-se no eixo central da trama como abalizador dos excessos e desacertos daquela comunidade. Ao gritar que se recusa a assinar sua libertação porque ela se daria a custo da desonra de seu próprio nome, Proctor contrapõe ao mecanismo da delação a opção pela ética, pela honestidade, pela verdade.

É justamente a dimensão crítica da peça ao processo de histeria coletiva motivador de denúncias e delações o que permite à trama enquadrar-se não apenas como projeção ou espelhamento, mas como reação ao Macarthismo, num momento em que a indignação e a denúncia a esses mecanismos de vigilância e acusação se faziam urgentes e necessárias, sobretudo porque, em meados dos anos 1950, ninguém se sentia seguro, já que as acusações do HUAC, obtidas sob pressão e medo de perda da própria posição, poderiam recair sobre os justos.

Orlandi (1999) notou que os mecanismos de vigilância têm grande influência no processo de significação da memória no presente. A peça de Miller, como já mencionado, mostra que os acontecimentos na Salém do século XVII e durante o Macarthismo podem ser observados pelo mesmo padrão de comportamento social.

\footnotetext{
14 "The Crucible is a study in power and the mechanisms by which power is sustained, challenged and lost".
} 
O medo de exclusão provoca vigilância coletiva, uns acusam os outros, um simples olhar pode ser suspeito, pode fazer um indivíduo falar ou silenciar por medo de punição e exclusão. Note-se, no entanto, que o ato de silenciar, assim como pode significar aceitação às regras do mecanismo de vigilância, pode também constituirse como resistência ao sistema, como o silêncio de Miller perante o HUAC.

Ironicamente, a memória da caça as bruxas da Salém histórica e a caça aos comunistas na peça tornou-se realidade para Miller em 1956, quando foi acusado pelo "olhar do poder" do HUAC, assim "a vida pagando à arte a bajulação sincera da imitação" (ROVERE, 1978, p. 317), o que mostra, de fato, que no corpus da análise deste trabalho, a vida real, a ficção e a memória se misturam. Miller silenciou porque não quis delatar e acusar para se salvar e assim protestou contra o HUAC e o Macarthismo.

Contudo, muitos acusados pelo HUAC não ficaram em silêncio, porque, como Bigsby (2005, p. 163) explica: "confissão mais delação era a fórmula para a segurança pessoal. Justamente por isso, a sanção de excomunhão estava disponível, a excomunhão da igreja verdadeira que é a América" ${ }^{16}$. Então, muitos acusados confessaram por medo de serem excluídos pela sociedade e de perder oportunidades de trabalho.

Assim, o mecanismo de vigilância do HUAC sugere que, em certos contextos, "falar é esquecer para que surjam novos sentidos num processo silenciador" (ORLANDI, 1999, p. 61). Os delatores diante do HUAC, na peça de Miller, e na Salém histórica mostram que, por via do falar e delatar, foi aberto o caminho para a construção de outros sentidos.

Um destes sentidos nos permite dizer que a memória foi ativada na peça de Miller de maneira a que não sejam esquecidas e silenciadas as atrocidades do panopticon; "a maquinaria diabólica [...] que não poupa ninguém" (FOUCAULT, 1998, p. 221). Senão a corte puritana, presa ao tempo pretérito, o HUAC e o Macarthismo ainda poderiam ser enfrentados em resistência. Em todo caso, a peça de Miller permanece como um chamado a que o olhar do poder, os efeitos perversos da delação e da informação sobre os outros e a exclusão dos que professam uma opinião diferente não saiam da memória.

\section{Considerações finais}

Nota-se, na conexão entre os acontecimentos históricos em Salém e a peça de Miller, que consiste de muitos implícitos e "já-ditos", como a repetição e a retomada das acusações, da agitação social, assim como da hipocrisia da cidade Puritana de Salém do século XVII favorecem uma visada crítica dos dados históricos do passado. Percebe-se também, por via da leitura da peça, um acontecimento discursivo, como outros implícitos são produzidos. Esses implícitos indiciam uma acusação de Miller ao endereço Macarthista na forma de uma metáfora, comparando a caça às bruxas na peça As Bruxas de Salém à caça aos comunistas durante o Macarthismo.

\footnotetext{
15 "life paying art the sincere flattery of imitation".

16 "confession plus informing was the formula for personal security. By the same token, the sanction of excommunication was available, excommunication from the true church that is America".
} 
A aproximação entre esses dois momentos históricos, abordados em suas práticas discursivas, mostra também que, por via da delação, entrevista em perspectiva crítica, foi aberto o caminho para a apreensão de outros sentidos. Um destes sentidos diz respeito à memória ativada pela peça de Miller, documento ou monumento que impede o esquecimento ou o silenciamento das atrocidades do panopticon, do HUAC, do Macarthismo. A peça de Miller exige que o olhar do poder, a delação e a exclusão do Outro não saiam da memória, servindo como exemplo ou como uma lição na vida cotidiana. Uma lição, porque, como diz Le Goff (2005, p. 535): um "documento não é qualquer coisa que fica por conta do passado, é um produto da sociedade que o fabricou".

Assim, os acontecimentos da Salém histórica, representados ficcionalmente na peça de Miller, assim como a histeria coletiva que se repete no Macarthismo, são produtos de suas sociedades opressoras, contra as quais, pessoas corajosas que lutaram por seus princípios reagiram, entrando na memória coletiva como exemplo, praticando uma resistência que pode ser retomada, citada e parafraseada em outros tantos casos e tempos de repressão e perseguição.

\section{Abstract}

Arthur Miller wrote The Crucible (1953), a play about a seventeenth century's witchhunt, as a metaphor of Communist-hunting during the McCarthy period, a period of persecution in the United States. In both occasions, the persecution's key piece was "naming": forcing a suspect to accuse others. In 1956, Miller, interrogated for having communist sympathies, refused to name, reinforcing the play as a denouncement of repression. The aims of this article are to connect the play to McCarthyism, applying, based on Pêcheux, regularization, social and discursive memory, omissions, the (un)said, implicits and (non)inscription into memory networks and applying Foucault's mechanisms of monitoring. It is concluded that the play, referring to the seventeenth century and to McCarthyism, is a document and monument that can be recovered by the collective memory as an example of mechanisms of monitoring and Pêcheux's concepts, allowing the play to be recaptured and cited in other cases of persecution.

Keywords: Arthur Miller's The Crucible, Mechanisms of Monitoring, Memory, Persecution.

\section{REFERÊNCIAS}

BENTLEY, E. (1978). The Innocence of Arthur Miller. In: WEALES, G (Org.). The Crucible: text and criticism. New York: The Viking Critical Library.

BIGSBY, C. (2005). Arthur Miller: a critical study. Cambridge: Cambridge University Press.

BROOKS, A. (1978). At the Theatre. In: WEALES, G (Org.). The Crucible: text and criticism. New York: The Viking Critical Library. 
COMITTEE ON UN-AMERICAN ACTIVITIES. Investigation of the Unauthorized Use of United States Passports-Part 4. Washington, 1956. Disponível em: $<$ https://www2.bc.edu/ reesdo/Miller testimony.pdf >. Acesso em: 03 jul. 2015.

CEIA, C. et al. E-Dicionário de Termos Literários. Lisboa, Portugal. Disponível em: $<$ http://www.edtl.com.pt/ >. Acesso em: 19 mai. 2015.

FINKELMAN, P. (2006). The Encyclopedia of American Civil Liberties: volume 1. New York: Routledge. Disponível em: <https://books.google.com.br/ > Acesso em: 02 jul. 2015.

FITZGERALD, B. (2007). McCarthyism: the red scare. Compass Point Books, Minneapolis. Disponívél em: <https://books.google.com.br/>. Acesso em: 2 jul. 2015. FOUCAULT, M. (1998). O Olho do Poder. In: Microfísica do Poder. 13ª edição. Rio de Janeiro: Edições Graal.

GLASS, A. (2013). Arthur Miller Testifies before HUAC, June 21, 1956. Politico Magazine. 21-06- 2013. Disponível em: <http://www.politico.com/story/2013/06/thisday-in-politics-093127 >. Acesso em: 29 jun. 2015.

HOBSON, H. (1978). Fair Play. In: WEALES, G (Org.). The Crucible: text and criticism. New York: The Viking Critical Library.

LE GOFF, J. (2003). Documento/Monumento. In: História e Memória. 5a edição. Campinas: Editora da Unicamp.

MILLER, A. (1978). The Crucible. In: WEALES, G (Org.). The Crucible: text and criticism. New York: The Viking Critical Library.

(2009). A Morte de um Caixeiro-Viajante e Outras 4 Peças de Arthur

Miller. Trad. José Rubens Siqueira. São Paulo: Companhia das Letras.

$\overline{\text { Guanabara. }}$

(1987). Uma Vida. Trad. Raul de Sá Barbosa. Rio de Janeiro: Editora

ORLANDI, E. (1999). Maio de 1968: os silêncios da memória. In: ACHARD, P. et al (Orgs.) Papel da Memória. Campinas: Pontes.

PÊCHEUX, M. (1999). Papel da Memória. In: ACHARD, P. et al (Orgs.). Papel da Memória. Campinas: Pontes.

ROVERE, R. H. (1978). Arthur Miller's Conscience. In: WEALES, G (Org.). The Crucible: text and criticism. New York: The Viking Critical Library.

WARSHOW, R. (1978). The Liberal Conscience in The Crucible. In: WEALES, G (Org.). The Crucible: text and criticism. New York: The Viking Critical Library. 